\title{
Homilia e realidade: elementos constitutivos da pregação homilética
}

\author{
Homily and reality: \\ constituent elements of homiletical preaching
}

Marcel Gustavo Alvarenga

\section{Resumo}

Este artigo tem como objeto formal a pregação cristã e objeto material a homilia litúrgica. A questão é a avaliação negativa das homilias litúrgicas, embora a homilia signifique um avanço da reforma litúrgica do Concílio Ecumênico Vaticano II, pois ela havia praticamente desaparecido do contexto litúrgico e se transformado em pregação de púlpito fora da missa. Porém, infelizmente, as homilias redundaram em uma prática insatisfatória ou, por vezes, negativa. Isto tem se constituído um problema grave para a Igreja e para o rito litúrgico. Retomaremos as orientações dos Papas Bento XVI e Francisco para atualizar nossas reflexões e apontar pistas para a solução do problema. Para isso, levaremos em consideração três elementos constitutivos apresentados na Instrução Geral do Missal Romano, a saber: Palavra, mistério e vida dos ouvintes. Nosso parecer é que, ao ponderar esses elementos, é possível fazer com que a homilia cumpra sua função mistagógica e atualize o anúncio da fé na vida de quem a escute.

Palavras-chave: Homilia. Liturgia. Preparação. Sentimento. Fé.

\begin{abstract}
This article has as its formal object the Christian preaching and the material object the liturgical homily. The question is a negative evaluation of the liturgical homilies although the homily means an advance of the liturgical reform of the Second Vatican Council, as it had practically disappeared from
\end{abstract}


the ritualistic context and turned into preaching of pulpit outside Mass. However, unfortunately, it has resulted in an unsatisfactory practice or negative. This has been a serious problem for the church and the liturgical rite. We will return to the guidelines of Popes Benedict XVI and Francis to update our reflections and point out clues for solving the problem. For this, we will take into consideration three constitutive elements presented in the General Instruction of the Roman Missal, namely: Word, mystery and life of the listeners. Our opinion is that, by considering these elements, it is possible to make the homily fulfill its mystagogical function and update the announcement of faith in the life of those who listen to it.

Keywords: Homily. Liturgy. Preparation. Feeling. Faith.

\section{Introdução}

Procuraremos examinar os elementos que fazem da homilia um sistema unitário de notas reais, cujo conteúdo favoreça sua pertinência e eficácia. O problema a partir do qual nos movimentamos é a valoração negativa das homilias. Antes do mais, temos de admitir que a homilia é um avanço da reforma litúrgica promovida pelo Concílio Ecumênico Vaticano II, pois ela havia praticamente desaparecido do contexto litúrgico e se transformado em pregação de púlpito fora da missa. O conteúdo da homilia não é um complexo de notas reais quaisquer, mas um complexo dessas notas sistematizadas de uma certa maneira, pois se fosse de outra, não seria homilia, seria outra coisa. É um risco a que a pregação litúrgica está sempre exposta. Talvez esteja aí o mais grave problema que enfrentamos: homilias que não são homilias, mas discursos acadêmicos ou especulações filosófico-teológicas ou até mesmo uma exposição espontânea sem um conteúdo formal. E parece-nos que aí está um caminho de análise que nos ajudará a buscar pistas de solução para o que nos propomos neste artigo.

\section{O que é a homilia?}

Homilia é um modo específico de pregação. Situada no contexto de uma celebração litúrgica, não é uma pregação desconexa, mas por sua própria natureza é "parte da própria liturgia". ${ }^{1} \mathrm{O}$ caráter litúrgico lhe confere uma

${ }^{1}$ SC 52. 
característica que lhe difere de catequeses, sermões e palestras. Pressupondo a fé de quem a ouve, seu objetivo é levar os ouvintes a um aprofundamento da fé cristã católica a fim de que testemunhem Jesus Cristo no mundo. ${ }^{2}$

Como parte constitutiva da liturgia, a homilia deve fluir naturalmente das leituras proclamadas, considerando a ação litúrgica que lhe sucederá. No caso de uma celebração eucarística, por exemplo, a homilia é como uma "dobradiça" a permitir a transição da liturgia da Palavra à liturgia Eucarística.

Etimologicamente, o termo grego homileo aparece no Novo Testamento indicando uma fala pessoal, conversacional, familiar. ${ }^{3}$ Considerando o exemplo dado por Jesus, a homilia faz com que a palavra proclamada seja cumprida (Lc 4,16-21) e, a partir das Escrituras, a assembleia seja capaz de perceber a ação de Deus em suas vidas, participar da fração do pão e testemunhar com alegria o encontro com o Ressuscitado (Lc 24,13-35). Quanto mais o homiliasta se aproxima do que Jesus fez na sinagoga de Nazaré e no caminho para Emaús, mais fielmente faz com que a homilia cumpra seu papel.

\section{A homilia vista por um escritor}

Em 1959, ao escrever o romance $O$ advogado do diabo, o escritor australiano Morris West colocou na boca de um de seus personagens uma contundente crítica à pregação cristã:

O senhor tocou num problema que há muito tempo me preocupa: a dificuldade de comunicação precisa entre o clero e leigos. É uma dificuldade que, ao invés de diminuir, aumenta. [...] A raiz disso, penso eu, é esta: a Igreja é uma teocracia governada por uma casta sacerdotal, da qual o senhor e eu somos membros. Temos uma linguagem própria, uma linguagem hierática, se quiser, formal, estilizada, admiravelmente adaptada a definições legais e teológicas. Desafortunadamente, também temos uma retórica própria que, como retórica do político, diz muito e comunica pouco. Mas não somos políticos. Somos professores, professores de uma verdade que afirmamos ser essencial para a salvação do homem. Contudo, como é que a pregamos? Falamos incessantemente de fé e esperança, como se estivéssemos empregando uma forma cabalística de encantamento. ${ }^{4}$

\footnotetext{
${ }^{2}$ NATIONAL CONFERENCE OF CATHOLIC BISHOPS, Fulfilled in your hearing, p. 18.

${ }^{3}$ NATIONAL CONFERENCE OF CATHOLIC BISHOPS, Fulfilled in your hearing, p. 24.

${ }^{4}$ WEST, M., O advogado do diabo, p. 83.
} 
O que temos de olhar por primeiro é se a crítica de West corresponde à realidade. E aqui apoiamo-nos no pensamento do filósofo basco Xavier Zubiri, que define de uma forma nova e inovadora o que é realidade e o que é realidade em ficção, pois West escreveu uma obra fictícia. Zubiri chama realidade em ficção de "ficto". Para ele, realidade é sempre maior do que ela mesma, daí sua dimensão transcendente. ${ }^{5} \mathrm{O}$ que nos interessa aqui é a definição de realidade como o apreendido da coisa real enquanto real. Esta apreensão, feita em modos diversos, tem seu modo primário e irredutível na apreensão primordial de realidade, que se dá direta, imediata e unitariamente. ${ }^{6}$ Portanto a apreensão primordial é sempre anterior, isto é, primária, aos seus desdobramentos em outras formas de apreensão sem nunca nos deixar sair da realidade. $\mathrm{O}$ que nos importa, ao insistir na apreensão primordial, é que tanto quanto a ação litúrgica inteira é um momento de acolher diretamente na realidade celebrativa a presença de Deus, a homilia, em sua dimensão litúrgica, é um momento de acolher Deus por meio da palavra celebrada.

Se um romancista apresenta uma valoração negativa da pregação cristã, isso tem a ver com algo apreendido anteriormente como real, pois diz Zubiri: "o que não se dá nem pode dar-se é um ficto que não tenha nada a ver com algo apreendido anteriormente como real". ${ }^{7}$ É claro que o romance é uma livre criação. Porém não é uma criação arbitrária no vazio. É realidade em ficção e não é ficção de realidade. ${ }^{8} \mathrm{~A}$ diferença é que realidade em ficção é sempre realidade, e ficção de realidade seria uma criação no vazio. Então, longe de ser ficção de realidade, estamos diante de uma realidade em ficção. Mesmo assim, a livre criação pode estar ou não em conformidade com o "como" das coisas reais, por se tratar mesmo de uma livre criação. ${ }^{9}$ Por isso é preciso buscar esse "como" da realidade homilética. E para fazê-lo, vamos conversar com o Magistério mais recente. Poderíamos tomar outro caminho, por exemplo, a pesquisa de campo. Mas a questão já avançou muito e se tornou preocupação magisterial.

\footnotetext{
${ }^{5}$ Neste artigo não é necessário desenvolver a dimensão transcendente da realidade.

${ }^{6}$ ZUBIRI, X., Inteligência e realidade, p. 187.

${ }^{7}$ ZUBIRI, X., Inteligência e logos, p. 73.

${ }^{8}$ ZUBIRI, X., Inteligência e logos, p. 73.

${ }^{9}$ ZUBIRI, X., Inteligência e logos, p. 73.
} 


\section{Duas palavras abalizadas: Bento XVI e Francisco}

Bento XVI já havia sinalizado em duas Exortações Apostólicas PósSinodais: Sacramentum Caritatis ${ }^{10}$ e Verbum Domini, ${ }^{11}$ a necessidade de melhorar a qualidade das homilias e de levar a sério o seu processo de preparação. Por sua vez, o Papa Francisco, na Exortação Apostólica Evangelii Gaudium, dedicou o terceiro capítulo ao anúncio explícito do Evangelho de Jesus Cristo. Boa parte desse capítulo enfatiza a importância da homilia como pregação ocorrente no contexto litúrgico. O que surpreende, a princípio, é a observação de que "são muitas as reclamações relacionadas a este ministério importante [...] muitas vezes, tanto eles [os fiéis] como os próprios ministros ordenados sofrem: uns a ouvir e outros a pregar". ${ }^{12}$ É preciso, portanto, reconhecer que há um obstáculo a ser superado, a fim de que a homilia possa ser "uma experiência intensa e feliz do Espírito, um encontro consolador com a Palavra, uma fonte constante de renovação e crescimento". ${ }^{13}$ Então aqui já podemos dizer que o "fictício" de West está de acordo com o "como" real das homilias litúrgicas.

A crescente crise da pregação na Igreja, apontada na obra de West e ressaltada pelo Papa Francisco, não é mera preocupação estilística, mas um fator que pode colapsar a liturgia e seu sentido. Quando não cumpre sua função, a homilia dispersa a atenção dos fiéis, impedindo-os de mergulhar mais profundamente no mistério celebrado. Se considerarmos que a homilia é parte da liturgia e que lhe cabe ser "uma explicação de algum aspecto das leituras da Sagrada Escritura [...] levando em conta tanto o mistério celebrado, como as necessidades particulares dos ouvintes", ${ }^{14}$ destacam-se nela três elementos inalienáveis, os quais podem fazer da homilia um sistema unitário de notas e não um complexo de notas quaisquer: a Palavra proclamada, o mistério celebrado e o contexto vivencial dos que participam da celebração. Tais elementos não são meros conceitos, mas realidades inegáveis e irredutíveis. Portanto, é muito importante sua apreensão primordial feita na liturgia sem nenhuma mediação ou distância. Esses elementos vão ser analisados já como uma proposta de solução para o dilema homilético.

\footnotetext{
${ }^{10} \mathrm{SCa} 46,53$

11 VD 59, 60.

12 EG 135.

${ }^{13}$ EG 135.

${ }^{14}$ IGMR 65.
} 


\section{A realidade da Palavra}

O Concílio Vaticano II afirmou que "deve a pregação, em primeiro lugar, haurir os seus temas da Sagrada Escritura e da liturgia". ${ }^{15}$ Então, a fonte principal do conteúdo homilético é a Sagrada Escritura e os textos litúrgicos, também chamados eucológicos. São um elemento inalienável da pregação. A atenção e a fidelidade aos textos bíblicos e litúrgicos são fundamentais para quem se propõe a pregar com seriedade.

Uma boa pregação exige, a princípio, que o homiliasta seja apaixonado pela Palavra, familiarizado com ela e disposto a ser tocado e transformado por ela. Sendo a homilia "um certo autorretrato da alma do pregador" 16 e "o ponto de comparação para avaliar a proximidade e a capacidade de encontro de um Pastor com o seu povo", ${ }^{17}$ só é capaz de atingir os fiéis aquele que em primeiro lugar se deixou atingir. Se faltar ao pregador a paixão e a convicção, ele não será capaz de anunciar o Evangelho eficazmente. Por isso o Papa Francisco indica que a preparação da pregação exige "um tempo longo de estudo, oração, reflexão e criatividade pastoral". ${ }^{18}$ Temos de ressaltar que estudo, oração, reflexão e criatividade pastoral constituem apreensão ulterior à realidade primordial da homilia. É por isso que o homiliasta tem de ser um apaixonado pela Palavra de Deus, senão pode cair em vários esquivos.

Um equívoco recorrente em diversas homilias consiste em proferi-las mergulhando fundo nas explicações exegéticas, em especulações filosóficas e teológicas ou na contextualização histórica. Uma homilia assim acaba sendo mais uma atividade acadêmica que celebrativa. Esse deslize rompe a unidade da celebração, oculta a simplicidade da Palavra revelada e se torna um verdadeiro obstáculo à participação ativa e eficaz dos fiéis, os quais não vão à celebração para estudar. Portanto, aqui tem uma profunda crítica de conteúdo: falta-lhe uma sistematização de notas reais, de tal forma que a homilia acaba sendo outra coisa: uma aula acadêmica. Esse mergulho fundo que acabamos de citar pode ser necessário numa boa preparação da homilia. Por isso, igualmente errônea é a atitude do pregador que não se dedica ao estudo e à meditação dos textos bíblicos, improvisando o conteúdo de seu discurso, embasando-se na mera espontaneidade e confiando na inspiração momentânea do Espírito Santo.

${ }^{15} \mathrm{SC} 35,2$.

${ }^{16}$ BOGAZ, A.; HANSEN, J. H., Homilia, p. 31.

${ }^{17}$ EG 135

${ }^{18}$ EG 135. 
Tal ato gera nos ouvintes mais confusão e marca uma postura de desonestidade e irresponsabilidade do homiliasta. ${ }^{19}$

Erra também o homiliasta que, deixando de lado a postura humilde necessária, passa a pregar segundo suas próprias ideias. Com isso ele incorre na prática de eisegese, ou seja, interpreta o texto a partir dos seus próprios pressupostos ou ideologias, forçando-o a afirmar algo muito alheio às intenções do autor. Tal atitude priva o texto bíblico de sua força enquanto Palavra revelada e a transforma em mera palavra manipulada. Já quando o pregador assume a humildade diante do texto bíblico, toma uma postura de quem está sempre aprendendo, sempre a caminho; e não a de quem já sabe o suficiente e não tem mais nada a aprender. É necessário, portanto, que o homiliasta se debruce sobre o sentido pleno das Escrituras, considerando os seus sentidos literal e espiritual. Mais do que conceitos ou conteúdos doutrinais, a homilia deve apresentar a pessoa de Jesus Cristo como seu ponto central. ${ }^{20}$

A homilia proporciona também o encontro pessoal com Jesus Cristo, quando consegue atualizar e inculturar a Palavra. Assim como no encontro do Ressuscitado com os discípulos de Emaús, é preciso que o pregador abra as Escrituras para seus ouvintes, fazendo-os entender que a Palavra nos é dita $h_{o j e} e^{21}$ e é também hoje que a Palavra ouvida se atualiza e se cumpre. Para isso, o pregador deve estar atento à mensagem central do texto sagrado a fim de explorar novas perspectivas e atualizar seu conteúdo de forma eficaz. ${ }^{22}$ Mais do que uma simples transcrição da realidade de outrora, faz-se necessário estabelecer vínculos entre nosso tempo e o tempo bíblico a fim de que, analisando os valores, as crises e os perigos das duas épocas, consiga mostrar aos fiéis que em nossos dias continuamos a história sagrada. ${ }^{23}$ Quando assim procede, o homiliasta consegue fazer com que a Revelação contida nas Escrituras ilumine a vida dos seus ouvintes.

Se a homilia visa apresentar Jesus Cristo aos ouvintes, o texto bíblico deve ser lido à luz do mistério pascal de Cristo. Assim, a compreensão escriturística que constitui o plano de fundo do discurso homilético, pois o primeiro plano é sempre do Senhor, deve possuir uma compreensão mistagógica. Isso permite já ressaltar aquela que é a segunda realidade a ser considerada: a do mistério celebrado.

\footnotetext{
${ }^{19}$ EG 145.

${ }^{20}$ VD 59.

${ }^{21}$ RUSSO, R., La homilía y su preparación en Evangelii Gaudium, p. 139.

22 BOGAZ, A.; HANSEN, J. H., Homilia, p. 29.

${ }^{23}$ BISCONTIN, C., Pregar a Palavra, p. 20.
} 


\section{A realidade do mistério}

Ao considerar o mistério celebrado na liturgia, é preciso lembrar que a beleza é elemento constitutivo da ação litúrgica, pois exprime e manifesta a glória de Deus. ${ }^{24}$ No contexto celebrativo, o conteúdo da bondade e da verdade é insuficiente se não estiver acompanhado pela beleza que, por ser a via própria de experiência religiosa ${ }^{25}$ atinge a todos e mergulha os fiéis no coração do mistério, de modo que "o que nela é humano se deve ordenar e subordinar ao divino, o visível ao invisível, a acção à contemplação, e o presente à cidade futura que buscamos". ${ }^{26}$

Nesse sentido, considerando o cuidado com todas as formas de linguagem na liturgia, ${ }^{27} \mathrm{o}$ discurso homilético deve também expressar beleza, não a partir dos fundamentos da oratória, mas a verdadeira beleza, que é "o amor de Deus que nos foi definitivamente revelado no mistério pascal". ${ }^{28}$ Novamente surge a necessidade de evidenciar a pessoa de Jesus Cristo como o centro da homilia: ele, que é chave de leitura das Escrituras, também é chave de leitura da celebração litúrgica. O mistério celebrado oferece ao pregador o horizonte a partir do qual a Palavra se faz sacramento e porta de entrada para a experiência pessoal e comunitária com Deus.

A função mistagógica da homilia consiste em fazer a transição entre a Liturgia da Palavra e a Liturgia Eucarística, conduzindo o povo da escuta à celebração e garantindo a unidade entre a mesa da Palavra e a mesa do Pão. ${ }^{29}$ Por isso urge ao homiliasta dispor de uma linguagem simbólica, capaz de tomar os fiéis pelas mãos e fazê-los adentrar reverentemente no mistério por meio de algum de seus aspectos, tais como a celebração do dia, o tempo litúrgico corrente, um rito específico, um artigo do Símbolo de Fé, entre outros. Isso era o que faziam com maestria os Padres da Igreja, principalmente em determinados momentos do ano litúrgico, como nos atesta este trecho de Santo Ambrósio:

Lavado e com ricos ornamentos, o povo avança para os altares de Cristo, dizendo: "Entrarei até o altar de Deus, ao Deus que alegra a minha juventude" [S1 42,4]. Depondo os despojos do antigo erro, sua juventude

\footnotetext{
${ }^{24} \mathrm{SCa} 35$.

${ }^{25}$ AZCUY, V. R, La "trama interna" de Evangelii Gaudium, p. 426.

${ }^{26} \mathrm{SC} 2$.

${ }^{27} \mathrm{VD} 40$.

28 VD 35.

${ }^{29}$ RUSSO, R., La homilía y su preparación en Evangelii Gaudium, p. 144.
} 
é renovada como a da águia, e se apressa para aproximar-se desse banquete celeste. Vem, portanto, e vendo o sacrossanto altar preparado exclama: "Preparaste à minha frente uma mesa". É esse povo que faz Davi falar, quando ele diz: "O Senhor me apascenta e nada me faltará; ele me colocou num pasto. Ele me conduz até a água que me reconforta”. E mais abaixo: "Ainda que eu ande na sombra da morte, não temerei o mal, porque tu estás comigo. Teu cetro e teu cajado me sustentaram. Preparaste diante de mim uma mesa bem à frente dos que me afligem. Ungiste a minha cabeça com óleo, e como é excelente a tua taça inebriante!" [S1 22,5.1-2.4-5]. ${ }^{30}$

Percebe-se como Santo Ambrósio, ao tratar dos mistérios da Iniciação Cristã aos neófitos, transita entre perícopes bíblicas e os ritos celebrados. Como pastor e pregador, sua preocupação não é tanto a de um exegeta que esmiúça os pormenores textuais, mas a de um mistagogo que, à luz da paixão, morte e ressurreição de Jesus Cristo, apresenta uma realidade humana tocada por Deus e completamente assumida por ele desde então.

O homiliasta, quando fiel ao mistério celebrado, procura interpretar as Escrituras segundo uma perspectiva pascal, considerando a celebração da Páscoa do Senhor como o ponto histórico sempre-presente ao qual convergem o passado e o futuro; o primeiro como memória e o segundo como antecipação. ${ }^{31}$ É precisamente a consciência disso que permite à Palavra manter seu frescor original e ser proclamada, vivida e cumprida no hoje de cada dia. A celebração da Eucaristia, ao atualizar o sacrifício de Cristo oferecido uma vez por todas, lança as bases para atualizar também a Palavra revelada definitivamente em Jesus Cristo.

Considerando o que foi apresentado até então, o pregador tem em mãos os textos bíblicos a serem interpretados, a perspectiva pascal como chave de leitura e a realidade do mistério como ponto de chegada almejado. Já são por si só elementos ricos e densos o suficiente para possibilitar aos fiéis uma experiência mistagógica. Entretanto, podem ocorrer dois equívocos que, por fim, tornam-se obstáculos aos ouvintes. De um lado, o racionalismo que se julga capaz de abarcar a totalidade do mistério e dissecá-lo categoricamente, esquecendo-se de que o resultado de qualquer dissecação é um objeto frio e sem vida. De outro lado, a delimitação do mistério num círculo hermético, que gera um discurso de termos cultos, mas inalcançáveis pela maioria dos fiéis, deixando-os admirados diante de um discurso de palavras bonitas e conteúdo

${ }^{30}$ AMBRÓSIO DE MILÃO, Sobre os Mistérios, VIII, 43

${ }^{31}$ BONNEAU, N., The Sunday Lectionary, p. 32-33. 
inacessível. Tanto o racionalismo quanto o hermetismo deturpam a realidade do mistério e impossibilitam aos fiéis a experiência do encontro com o Cristo ressuscitado.

Importante ressaltar também que, como parte integrante da ação litúrgica, o bom êxito da homilia depende da coesão harmônica das demais partes que compõem o mesmo rito. ${ }^{32}$ Quando os cantos são bem cantados, as leituras bem proclamadas e a disposição espaço-temporal de todos os elementos equilibrada em devidas proporções, uma homilia bem preparada consegue se encaixar perfeitamente e produzir êxtase e deleite na assembleia ouvinte. Do contrário, a falta de zelo, dignidade e brio para com a celebração em sua integridade, gerando ruídos que distorcem a beleza, confundem os fiéis e tiram a atenção do que há de mais importante no conteúdo homilético. Por isso, toda a equipe de liturgia é, de forma estendida, responsável pela qualidade da recepção da homilia.

\section{A realidade vivencial dos ouvintes}

Levando em consideração que a celebração eucarística atualiza o mistério celebrado, o pregador deve ter conhecimento suficiente sobre o contexto em que a comunidade vive a fim de poder estabelecer relações consolidadas entre o texto bíblico, o mistério celebrado e a vida do povo de Deus. Isso é ressaltado por Francisco ao tomar as homilias como medida da proximidade entre pastor e povo, como já citamos.

Nesse aspecto a homilia depende do vínculo pastoral e existencial entre o homiliasta e a assembleia. Quanto mais forte for esse vínculo, maior a possibilidade de uma fala acessível, pertinente e transformadora. Um pastor que realmente exala o cheiro de suas ovelhas é capaz de perceber e assumir os dramas, conflitos, esperanças e ideais da comunidade à qual pertence. Torna-se atento às indagações mais profundas e às necessidades mais urgentes do povo, aprendendo a ler a mensagem de Deus nos acontecimentos da vida do povo. ${ }^{33}$ Caso lhe falte essa capacidade de detecção, estará fadado a oferecer respostas para questões não levantadas e fórmulas universais cheias de clichês e lugarescomuns que nem de longe tocam a vida de quem lhe escuta.

Considerarmos Jesus Cristo como modelo de pregador, constatamos que seus ensinamentos sempre partiam dos fatos que tocavam a vida das pessoas. O Reino de Deus era por ele comparado aos semeadores (Mt 13,1-9) e aos

\footnotetext{
32 TRUDEL, J., Homilia, p. 57.

${ }^{33}$ EN 137.
} 
pescadores (Mt 13,47-52), ao pastor que procura a ovelha perdida (Lc 15,3-7) e à mulher que mistura farinha e fermento para preparar um pão (Mt 13,33). O perdão e a misericórdia eram exemplificados na figura de um pai que perdoa o filho pródigo (Lc 15,11-32) e de um estrangeiro que interrompe sua viagem para cuidar de uma vítima de assalto cuja vida corre perigo (Lc 10,25-37). A sensibilidade de percepção de Jesus Cristo faz com que ele ponha em evidência a flor do campo (Mt 6,28), as aves do céu (Mt 6,26) e até mesmo a mísera doação de uma viúva ao tesouro do Templo (Mc 12,41-44). Partindo desses elementos concretos, a mensagem de Jesus atingiu a todos que o ouviam.

Ora, dado que ao longo de dois milênios a rotina dos povos se transformou quase que completamente, faz-se necessário haver uma adequação também das figuras de linguagem e das imagens usadas na pregação. A imagem de um pastor, por exemplo, dificilmente transmite às pessoas de hoje o mesmo que transmitia aos contemporâneos de Jesus. Contudo, podem existir nesta figura concentrações históricas que a fazem compreensível. Para atualizar adequadamente a Palavra, o pregador precisa ter sensibilidade o bastante para conhecer as circunstâncias em que vive o povo que lhe ouve pregar. ${ }^{34}$ São oportunas as colocações? São pertinentes as admoestações? Os exemplos práticos partem daquilo que o povo realmente vive ou são meros idealismos fantasiados pelo homiliasta? Quanto mais os símbolos e imagens usados na pregação forem buscados no contexto da assembleia, mais a mensagem do Evangelho chegará ao coração de todos. ${ }^{35}$

É necessário também levar em conta que o objetivo da homilia não é proporcionar uma simples fruição estética, mas conduzir os fiéis da Palavra ao Mistério e do Mistério à vida. ${ }^{36}$ Ao discursar sobre a vida cristã e entrar nos âmbitos da teologia moral, o pregador deve levar em conta que ele mesmo se faz mensagem a partir da forma com que vive aquilo que prega ${ }^{37} \mathrm{O}$ homiliasta prega não só ao demonstrar terna proximidade aos fiéis e amor crescente pelas Escrituras, mas também quando ele mesmo, em sua vida, dá testemunho da mensagem pregada, mostrando que se deixou ser tocado e ferido pela Palavra. ${ }^{38}$ Isso nada mais é do que pôr em prática o que o bispo pede ao diácono no dia de sua ordenação: "recebe o Evangelho de Cristo, do qual foste constituído

\footnotetext{
${ }^{34}$ RUSSO, R., La homilía y su preparación en Evangelii Gaudium, p. 143.

${ }^{35}$ EG 145.

${ }^{36} \mathrm{EG} 138$.

${ }^{37}$ RUSSO, R., La homilía y su preparación en Evangelii Gaudium, p. 140.

${ }^{38}$ EG 150.
} 
mensageiro; transforma em fé viva o que leres, ensina aquilo que creres e procura realizar o que ensinares". ${ }^{39}$

Na dinâmica de conhecer a realidade do povo é imprescindível encontrar formas de fazer ressoar o conteúdo querigmático de forma que ele leve o povo ao amadurecimento na fé. Nesse ponto é necessário ressaltar a importância das diversas formas de religiosidade popular previamente semeadas pelo Espírito Santo e tomá-las como ponto de partida. ${ }^{40}$ Ao se atentar às tradições religiosas populares, o pregador será capaz de encontrar e utilizar a voz maternal que é própria à Igreja e falar aos corações dos seus ouvintes. A crítica de Morris West que iniciou este artigo continua: "Falamos ao povo todos os domingos, mas nossas palavras não chegam até os que nos ouvem, pois que esquecemos a nossa língua materna". ${ }^{41} \mathrm{Se}$ os pregadores se atentarem à voz do Espírito já presente na vivência eclesial das comunidades, saberão encontrar meios de evitar uma pregação hermética e conseguirão traduzir a riqueza inesgotável do Mistério na realidade da vida do povo.

\section{Conclusão}

Neste estudo focamos em três importantes elementos basilares da pregação homilética a partir de uma perspectiva realista. As Escrituras, o Mistério celebrado e o contexto em que a comunidade está inserida. São fundamento do discurso e linhas-mestras para o desenvolvimento de seu conteúdo. Aí poderíamos dizer, usando o pensamento zubiriano sobre a realidade, que sendo o conteúdo a homilia um sistema unitário de notas reais, e não um complexo de notas reais quaisquer, mas um complexo de notas sistematizada de uma certa maneira, apresentamos três elementos que mostram o como da sistematização homilética: a homilia tem de ser bíblico-eucológica, profundamente envolvida no mistério celebrativo e na vida dos participantes. Esta é a atualidade de uma homilia litúrgica.

Infelizmente, estamos em tempos de improvisos inconsequentes e da tentação de encontrar as coisas todas prontas com facilidade. É mister reafirmar a necessidade de levar a sério a preparação da homilia. Pregações de cunho acadêmico e densas de especulações filosófico-teológicas ou de curiosidades históricas ou mesmo de uma comunicação rasa baseada em sátiras e de conteúdo humorístico podem até agradar os ouvidos e prender a atenção, mas

\footnotetext{
${ }^{39}$ Pontifical Romano, 238.

${ }^{40}$ DAp 262.

${ }^{41}$ WEST, M., O advogado do diabo, p. 84.
} 
não elevam ao mistério. Traem sua finalidade e esvaziam as chances de proporcionar o encontro entre Deus e seu povo. Mais do que dizer o que a assembleia quer ouvir como deleite, o homiliasta deve se preocupar em anunciar o que é preciso ser dito da parte de Deus e da Igreja.

Por fim, o equilíbrio entre os elementos fundamentais, o conteúdo e o método fazem transparecer a importância da harmonia no discurso homilético. Bebendo das fontes da realidade e sendo lapidada cuidadosamente pelo pregador, "a homilia é uma obra de arte, devendo ter graça e beleza, devendo fascinar os fiéis e deixar marcas no coração e na mente". ${ }^{42}$

\section{Referências bibliográficas}

AMBRÓSIO DE MILÃO. Sobre os Mistérios. São Paulo: Paulus, 1996.

AZCUY, V. R. La "trama interna" de Evangelii Gaudium: Ensayo sobre la fuerza de la espiritualidade evangelizadora. Perspectiva Teológica, v. 46, n. 130, p. 407-432, set./dez. 2014.

BENTO XVI, PP. Exortação Apostólica Pós-Sinodal Sacramentum Caritatis. São Paulo: Paulinas, 2007.

BENTO XVI, PP. Exortação Apostólica Pós-Sinodal Verbum Domini. São Paulo: Paulinas, 2011.

BISCONTIN, C. Pregar a Palavra: A ciência e a arte da pregação. Brasília: CNBB, 2017.

BOGAZ, A. S.; HANSEN, J. H. Homilia. São Paulo: Paulinas, 2018.

BONNEAU, N. The Sunday Lectionary: Ritual word, Paschal shape. Collegeville: The Liturgical Press, 1998.

CONCÍLIO ECUMÊNICO VATICANO II. Constituição Sacrosanctum Concilium. In: VIER, F. (Org.) Compêndio do Concílio Vaticano II: Constituições, decretos, declarações. Vozes: Petrópolis, 2016. p. 259-306. CONGREGAÇÃO PARA O CULTO DIVINO E A DISCIPLINA DOS SACRAMENTOS. Pontifical Romano. São Paulo: Paulus, 2000.

${ }^{42}$ BOGAZ, A.; HANSEN, J. H., Homilia, p. 84. 
CELAM. Documento de Aparecida: Texto conclusivo da V Conferência Geral do Episcopado Latino-Americano e do Caribe. Brasília: CNBB; São Paulo: Paulus / Paulinas, 2007.

FRANCISCO, PP. Exortação Apostólica Evangelii Gaudium. São Paulo: Paulus / Loyola, 2014.

INSTRUÇÃO Geral do Missal Romano e Introdução ao Lecionário. Brasília: CNBB, 2008.

NATIONAL CONFERENCE OF CATHOLIC BISHOPS. Fulfilled in your hearing: The homily in the Sunday assembly. Washington, DC: United States Catholic Conference, 1982.

PAULO VI, PP. Exortação Apostólica Evangelii Nuntiandi. São Paulo: Paulinas, 2008.

RUSSO, R. La homilía y su preparación en Evangelii Gaudium. Medellín, v. 40, n. 158, p. 125-149, abr./jun. 2014.

TRUDEL, J. Homilia: Formação e arte de comunicar. São Paulo: Paulus, 2015. WEST, M. O advogado do diabo. Rio de Janeiro: BestBolso, 2013.

ZUBIRI, X. Inteligência e logos. São Paulo: É realizações, 2011.

ZUBIRI, X. Inteligência e realidade. São Paulo: É realizações, 2011.

Marcel Gustavo Alvarenga Mestrando em Teologia na Pontifícia Universidade Católica de São Paulo Campinas / SP - Brasil E-mail: guto.alvarenga@gmail.com

Recebido em: 02/07/2020 Aprovado em: 18/02/2021 